\title{
LOS CONTORNOS DEL DEBER DE CONSEJO COMO EXPRESIÓN DE LA COLABORACIÓN Y COMO TÉCNICA DE PROTECCIÓN
}

\author{
THE CONTOURS OF THE DUTY TO COUNCIL AS AN \\ EXPRESSION OF COLLABORATION AND TECHNIQUE OF \\ PROTECTION
}

JUAN LUIS GOLDENBERG SERRANO***

Prof. de Derecho Civil

P. Universidad Católica de Chile

Santiago - Chile

\section{RESUMEN}

El presente trabajo pretende configurar los deslindes del deber de consejo, especialmente ofreciendo los elementos que lo distinguen del deber general de información. Lo anterior, sobre la base de la identificación de su justificación en la órbita de la buena fe, de su contenido implícito desde la perspectiva de los deberes y cargas que su operatividad implica y de las consecuencias jurídicas de su infracción. Al efecto, el objetivo se centra en la necesidad de apreciar todos los mentados extremos a fin de observar el deber de consejo como el resultado de la necesaria colaboración entre las partes en la negociación de un cierto tipo de contratos, con alta consideración técnica, de modo de poder intensificar las fórmulas de protección del contratante legítimamente ignorante.

* Profesor asociado del Departamento de Derecho Civil, Pontificia Universidad Católica de Chile. Doctor en Derecho de la Universidad de Salamanca. Dirección: Avda. Libertador Bernardo O’Higgins 340, Santiago. Correo electrónico: jgoldenb@uc.cl.

**Este trabajo se inscribe en el proyecto FONDECYT Regular No. 1180329 ("Hacia un sistema preventivo de protección de los consumidores financieros: la asignación de deberes y cargas a los concedentes del crédito para una correcta distribución del riesgo de sobreendeudamiento").

Artículo recibido el 13 de septiembre de 2018 y aceptado para su publicación el 19 de noviembre de 2018. 
Palabras clave: Derecho de contratos, deber de información, deber de consejo, colaboración.

\section{ABSTRACT}

This paper aims to construe the boundaries of the duty to advice, especially by offering the elements that distinguish it from the general duty to inform. Such, on the basis of identifying its justification in the orbit of the good faith, in its implicit content from the perspective of the duties and burdens that its functioning requires, and the consequences of its breach. In this sense, the objective focusses in the necessity to appreciate all the aforementioned elements to observe the duty to advice as the result of the need of collaboration among the parties during the negotiation of a certain kind of contracts, with strong technical features, in order to intensify the protection of the party that is legitimately ignorant.

Keywords: Contract law, duty to inform, duty to advice, collaboration.

\section{INTRODUCCIÓN}

La noción de consejo, entendido por la Real Academia Española como la "opinión que se expresa para orientar una actuación de una determinada manera", sólo aparece en nuestro Código Civil en el contexto del mandato, a la luz del art. 2119 CC, a fin de negar la producción de algún efecto obligacional, salvo en cuanto este se presente de manera maliciosa. ${ }^{1}$ Otro tanto ocurre en el Código de Comercio (CCom), en el que el consejo no produce una recalificación de la responsabilidad del socio comanditario, al entender que éste no constituye un acto de administración (artículo 487, $\mathrm{n}^{\circ} 3 \mathrm{CCom}$ ), al

${ }^{1}$ El ejemplo dado al efecto por Domat, Jean, Les loix civiles dans leur ordre naturel, Jean Baptiste Coignard \& Librairie ordinaire du Roi, París, 1689, p. 454, es bastante paradigmático, puesto que se pone en el caso en que el consejo está dado para prestar a quien el acreedor no conoce, sustentado en la idea de la seguridad del pago. Sobre una interpretación de la norma en el contexto nacional, vid. Stitchkin Branover, David, El mandato civil, $5^{\text {a }}$ edición actualizada por Gonzalo Figueroa Yáñez, Editorial Jurídica de Chile, Santiago, 2008, pp. 232-239, y BARros, Enrique; Rioseco, Andrés, "Responsabilidad de quien da un mal consejo", en: Vidal Olivares, Á., Severín Fuster, G. y Mejías Alonso, C., (eds.), Estudios de Derecho Civil X. Jornadas Nacionales de Derecho Civil. Valparaíso, 2014, Thomson Reuters La Ley, Santiago, 2015, pp. 635-640. 
tiempo que se advierte que aquél puede generar responsabilidad, debido a su deficiencia, para el práctico y piloto porque lo ha otorgado al capitán para el cumplimiento de sus deberes de cuidado respecto a la navegación (artículo 909). Más llamativo, como veremos, es la completa ausencia de toda referencia al punto en el contexto de la Ley $\mathrm{N}^{\circ} 19.496$, sobre protección de los derechos de los consumidores ("LPDC").

En contraste, existen otros casos en los que el deber de asesoramiento se inserta en la lógica precontractual o contractual, según el supuesto, como en la órbita del contrato de seguros (artículos 529.1 CCom y 57 del Decreto Ley $\mathrm{N}^{\circ} 251$, de 1931) o de los intermediarios financieros (artículo 169 de la Ley $\mathrm{N}^{\circ} 18.045$, de 1981, aunque en este caso sólo refiera al contenido de la prestación como "asesoría financiera"), sin nombrar aquellos casos en que, lógicamente, el propio contenido contractual se refiere al consejo como parte de un cierto arrendamiento de servicios (siguiendo a STITCHKIN, por ejemplo, "como en el caso del médico o del abogado que atiende consultas relacionadas con su profesión, mediante remuneración"). ${ }^{2}$

Ahora bien, más allá de identificar los contornos de los deberes de consejo en tales ejemplos, nos interesa analizar los supuestos en los que, en atención a las circunstancias, puede colegirse su existencia, especialmente sobre la base fundante del principio de la buena fe. Del modo expuesto por Eyzaguirre BAEZA y Rodríguez Diez, la formulación habitual de dicho principio, en atención a la falta de definición propia de las codificaciones decimonónicas, se resolvería en la idea de que cada parte debería tomar en cuenta el legítimo interés de la contraparte, ${ }^{3}$ lo que, veremos, resulta coincidente con las bases del deber de consejo. De esta forma, más allá de determinar la dimensión negativa que precave la realización de conductas lesivas, el aspecto destacable es el referido a sus aspectos positivos, revisados desde la lógica de la cooperación, ${ }^{4}$ incluso,

\footnotetext{
${ }^{2}$ STitchkin, cit. (n. 1), p. 238. Lo anterior, a pesar de la previsión inicial dada por los autores más clásicos en el sentido de negar cualquier clase de responsabilidad, incluso en el ámbito profesional, dado que el consejo no genera la obligación de seguirlo por parte de quien lo recibe. En este sentido, Barros y Rioseco, cit. (n. 1), p. 640.

${ }^{3}$ Eyzaguirre Baeza, Cristián; Rodríguez Diez, Javier, "Expansión y límites de la buena fe objetiva - A propósito del Proyecto de Principios Latinoamericanos de los Contratos", Revista Chilena de Derecho Privado, 2013, No 21, p. 144. Así también, Romain, Jean-Francois, Théorie critique du principe général de bonne foi en droit privé, Bruylant, Bruselas, 2000, p. 857, aunque destacando que en la órbita precontractual se da cuenta del principio de la buena fe especialmente para justificar las consecuencias de la ruptura de las tratativas preliminares.

${ }^{4}$ Demogue, René, Traité des obligations en général. II. Effets des Obligations, Librairie Arthur Rousseau, París, 1931, T. VI, pp. 17-18. Sobre el concepto de cooperación, que, desde el punto de vista del deudor, importa ejecutar la obligación con la mayor utilidad al acreedor, $\mathrm{y}$, desde la perspectiva
} 
sobre los estándares del denominado "solidarismo contractual". ${ }^{5}$ A partir de esta idea, se han formulado una serie de deberes adyacentes a la prestación, incluyendo, como ha resaltado nuestra jurisprudencia, "la cooperación, colaboración, asesoramiento e información entre las partes, comportándose de manera activa, pues le asiste la obligación de salvaguardar el interés de la otra parte". ${ }^{6}$

En este sentido, aun cuando la buena fe se propicie como un concepto abierto, que debe ser completado por medio de la actividad jurisdiccional, ello no implica una escapatoria, sea de procesos lógicos o de valoraciones axiomáticas, según el punto de partida que se tome. ${ }^{7}$ Este aspecto se refiere a la necesaria revisión de la situación de hecho que se presenta ante el tribunal $\mathrm{y}$, en tal consideración, apreciar los contornos de la relación jurídica sobre los pilares admitidos en el mandato contenido en el artículo $1546 \mathrm{CC}$, requiriendo de la reconducción a la naturaleza de la obligación, la ley o la costumbre. ${ }^{8}$ Omitiendo los casos en que los que ella puede efectuarse a estos dos últimos elementos, la extensión del contrato en razón a la naturaleza de la obligación supone, entonces, la identificación de aquellos aspectos "no declarado(s), pero que resulta(n) necesario(s) para la total satisfacción de la prestación obligacional de la que se trata".

Conforme a lo anterior, el plan a seguir es el siguiente: en primer término, pretendemos deslindar el deber de consejo del de información. Así, si bien podrá observarse que entre ellos existe una gran proximidad, las diferencias se presentarán en torno a su graduación, a su naturaleza y a su operatividad (Sección II). Luego, se verificarán los supuestos fácticos que permiten sostener el surgimiento de un deber de consejo, especialmente en el ámbito

de este último, como el ofrecimiento de toda la ayuda necesaria para el cumplimiento del deudor, vid. Picod, Yves, Le devoir de loyauté dans l'exécution du contrat, LGDJ, París, 1989, p. 104.

${ }^{5}$ Mazeaud, Denis, "Solidarisme contractuel et réalisation du contrat," en: Grynbaum, L.; Nicod, M. (eds.), Le solidarisme contractuel, Economica, Paris, 2004, pp. 58-59.

${ }^{6}$ Corte Suprema, 27 de enero de 2012, Rol No 1180-2012; Corte Suprema, 25 de abril de 2012, Rol N ${ }^{\circ}$ 7145-2010; Corte Suprema, 2 de mayo de 2012, Rol N 3965-2011; y Corte Suprema, 2 de septiembre de 2014, Rol N 14.243-2013 (los destacados son nuestros).

7 WIEACKer, Franz, El principio general de la buena fe (trad. José Luis Carro), Civitas, Madrid, 1977, pp. 32-41.

${ }^{8}$ Como expresa Guzmán Brito, Alejandro, "La buena fe en el Código Civil de Chile", Revista Chilena de Derecho, 2002, Vol. 29, $\mathrm{N}^{\circ} 1$, p. 12, la formulación del principio de la buena fe objetiva en el artículo 1.546 CC no sigue igual estructura que sus antecedentes en el Code Civil francés (artículos 1.134 y 1.135), al tiempo que la norma patria supone la expansión del contrato en la buena fe, y, conforme a ella, se fijan los estándares para ello.

${ }^{9}$ GuzMán Brito, cit. (n. 8), p. 17. 
precontractual, con la pretensión de dar cuenta de su finalidad propia, cual es asistir a una de las partes en la deliberación sobre la conveniencia o no de contratar, o, al menos, los términos en los que se llevará a cabo tal contratación (Sección III). Posteriormente, se pretende dar luces sobre los deberes y cargas implícitos en el deber de consejo, de manera de observar la dinámica por medio de la cual puede cumplirse con la finalidad antedicha (Sección IV). Y, finalmente, se dará cuenta de las consecuencias jurídicas relativas a su incumplimiento (Sección V). Todo ello, para terminar con las conclusiones de rigor (Sección VI).

\section{DISTINCIÓN ENTRE EL DEBER DE CONSEJO Y EL DEBER DE INFORMACIÓN}

Sobre la base de las asimetrías informativas que pueden darse en el marco de la contratación, es usual derivar deberes de información en un sentido amplio. A partir de lo anterior, suele construirse la idea de hacer soportar a quien se encuentra "bien informado" la obligación de informar al que no lo está. ${ }^{10}$ Se ha indicado que dicho deber "tiene por finalidad acercar concretamente, en tanto sea posible, a la igualdad teórica de las partes en la defensa de sus propios intereses que debe conducir a la justicia conmutativa por un justo procedimiento contractual". ${ }^{11}$ La información, nos señala BERTHIAU, reposa sobre la idea de la protección del equilibrio contractual, y, a pesar de que pareció cubierta por la lógica del "emptor debet ese curiosis", renació con fuerza en el siglo XX, especialmente desde la óptica de la buena fe. ${ }^{12}$ Ello, aun cuando se insista que su comprensión deba soportar los límites propios de la excepcionalidad, ${ }^{13}$ propiciando una aplicación más general del principio de autoprotección o de autorresponsabilidad. ${ }^{14}$ La función misma de la obligación de información, agrega el citado autor, es la de establecer la igualdad de los contratantes ante la ley contractual, en formación o ya existente, por medio

\footnotetext{
${ }^{10}$ LuCAS DE LeyssaC, Claude, "L'obligation de renseignement dans les contrats", en: Loussouarn, Y.; Lagarde, P. (dirs.), L'information en Droit privé, Librairie Générale de Droit et de Jurisprudence, París, 1978, p. 305.

${ }^{11}$ Ghestin, Jacques; Louseau, Grégoire; Serinet, Yves-Marie, La formation du contrat, LGDJ, París, 2013, T. I., p. 1259.

${ }^{12}$ Berthiau, Denis, Le principe d'égalité et le droit civil des contrats, LGDJ, París, 1999, pp. 132-133.

${ }^{13}$ Mouly-Guillemand, Clémence, Retour sur l'article 1135 du Code Civil. Une nouvelle source du contenu contractuel, LGDJ, París, 2006, pp. 394-395.

${ }^{14}$ De la Maza Gazmuri, Iñigo, "Tipicidad y atipicidad de los deberes precontractuales de información", Revista de Derecho P. Universidad Católica de Valparaíso, 2010, XXXIV, p. 79.
} 
del conocimiento, ${ }^{15} \mathrm{y}$, a partir de lo anterior, dar plena aplicación a la máxima conforme a las cuales volenti non fit iniuria.

Pero este deber se distingue por tener un carácter neutro, ${ }^{16}$ que se satisface por medio de la transmisión de un mensaje objetivo y general, ${ }^{17}$ en que simplemente se da cuenta de los aspectos más relevantes del contrato. ${ }^{18}$ En consecuencia, la cuestión se centra en asumir que por la mera transmisión de aquella información que una de las partes se encuentra imposibilitada de obtener, o, al menos, se encuentra en una situación de difícil u onerosa obtención, sin pretender que quien debe dar cumplimiento al citado deber deba efectuar gestión ulterior alguna a la comunicación. De esta manera, deberá asumirse que se constituye como una especie de obligación de resultado, ${ }^{19}$ en la que la verificación se da en términos en que ella se ha entregado de manera completa, clara y oportuna, pero sin tomar en cuenta la diligencia de quien ha entregado la información ni la posición en la que efectivamente queda su acreedor una vez la ha recibido. En esta esfera, por tanto, todavía no es apreciable una particular preocupación por parte del ordenamiento a fin de asegurar una mejor comprensión del contenido del mensaje por parte de su destinatario, ${ }^{20} \mathrm{ni}$, menos aún, se provoque un alineamiento entre sus intereses y los términos particulares de la contratación. Por ello, suponiendo el cumplimiento de dicha obligación, su beneficiario ya no podrá alegar el haber padecido un error inexcusable, $y$, mucho menos, que ha sido víctima de reticencia, aun cuando, en atención a su situación, la información entregada le haya resultado finalmente inútil, puesto que no cuenta con los conocimientos suficientes para entender completamente su contenido.

En esta órbita, el deber de consejo también atendería a la pretensión de lograr una justicia procedimental en la formación del consentimiento, y de ahí que la cercanía entre uno y otro deber haya significado tanto debate

\footnotetext{
${ }^{15}$ Berthiau, cit. (n. 12), p. 135.

${ }^{16} \mathrm{~F}$ IL, Patrice, L'obligation d'information et de conseil en matière d'assurance, Presses Universitaires d'Aix-Marseille, Aix-en-Provence, 1996, p. 73.

${ }^{17}$ BouCARD, François, Les obligations d'information et de conseil du banquier, Presses Universitaires d'Aix-Marseille, Aix-en-Provence, 2002, p. 21.

${ }^{18}$ Barros y Rioseco, cit. (n. 1), p. 634.

${ }^{19}$ Khoury, Hichem, L'information et le conseil dus preneur d'assurance, Presses Universitaires D'AixMarseille, Aix-en-Provence, 2011, p. 27.

${ }^{20}$ Barrientos Zamorano, Marcelo, "El deber precontractual de información en el contrato de seguro, un producto financiero y de consumo: Estudio de sus fuentes", Revista Chilena de Derecho, 2015, Vol. 42, $\mathrm{N}^{\circ}$ 2, p. 432.
} 
doctrinal. ${ }^{21}$ Como expresa Gómez CALle, el problema se centra en que "las mismas circunstancias que pueden determinar el deber de informar de una de las partes puede generar, en ciertos casos, un deber de consejo adicional", ${ }^{22}$ a lo que Llobet i AGUADo agrega que "el deber de consejo incluye la obligación de información en sentido estricto, pero no al revés". ${ }^{23}$ Conforme a ello, suele indicarse que entre uno y otro no hay una diferencia en cuanto a su naturaleza, dado que en ambos se supone la transmisión de un mensaje (aunque sus características sean diversas), sino únicamente de graduación. ${ }^{24}$

No obstante, nos parece que frente a tales aseveraciones resulta necesario agregar ciertos matices. El deber de consejo importa la necesidad de acompañar a la contraparte en la reflexión que resulta necesaria para la declaración de una voluntad afirmativa, de ser el caso, para el perfeccionamiento del contrato. ${ }^{25} \mathrm{La}$ deliberación constituye una fase preparatoria a la manifestación de la voluntad, suponiendo una instancia de duda, en la que la parte proyecta las consecuencias de sus decisiones, sean positivas o negativas. Supone que la contratación no se produce como consecuencia de un mero impulso automático, especialmente en aquellas órbitas en las que se concita un aspecto técnico de intensidad. ${ }^{26}$ Es estos casos, deberá notarse que el proceso deliberativo se encuentra en riesgo, en el sentido de que la parte no tiene las capacidades o habilidades suficientes para la expresión de una voluntad en la que pueda representarse como ciertas todas las consecuencias de la contratación. La información que

\footnotetext{
${ }^{21}$ LuCAS DE LeYSSAC, cit. (n. 10), p. 306; Chardin, Nicole, Le contrat de consommation de crédit et l'autonomie de la volonté, Librairie Générale de Droit et de Jurisprudence, París, 1988, p. 156; GómEZ CALLE, Esther, Los deberes precontractuales de información, La Ley, Madrid,1994, p. 119; McMeel, Gerard; VIGGO, John, Financial advice and financial products. Law and liability, Oxford University Press, Oxford, 2001, p. 31; Khoury, cit. (n. 19), p. 78; De la Maza Gazmuri, Íñigo, "Consentimiento informado, una visión panorámica", Ius et Praxis, 2010, Año 16, № 2, p. 98. GHestin, LoIseau y SERINET, cit. (n. 11), p. 1270, por ejemplo, sostienen que la obligación precontractual de información puede consistir "plus précisement en une mise en garde ou des conseils". De igual manera, sostienen (p. 1271) que se imponen a su deudor la obligación de entregar al beneficiario información, alertas o consejos necesarios para el uso útil y seguro de la prestación, o, en otras palabras, que responda a su uso.

${ }^{22}$ Gómez CAlle, cit. (n. 21), p. 120.

${ }^{23}$ Llobet i Aguado, Josep, El deber de información en la formación de los contratos, Marcial Pons, Madrid, 1996, p. 34.

${ }^{24}$ GlansdorfF, François, "Introduction générale", en: Glansdorff, F. (director), Les obligations d'information, de renseignement, de mise en garde et de conseil, Lancier, Bruselas, 2006, p. 24.

${ }^{25}$ En este sentido, la Corte de Apelaciones de Antofagasta, 2 de mayo de 2012, Rol N 373-2011, señaló lo siguiente en su considerando décimo: "(e)ste deber de información es completado por el 'deber de consejo', que supone recomendar un camino de acción de conformidad con la práctica médica".

${ }^{26}$ ChARdin, cit. (n. 21), pp. 66-67.
} 
le puede haber sido entregada podrá resultarle inútil, no por el hecho de la oscuridad en la redacción o en la forma en la que la ha recibido, sino porque no maneja adecuadamente los términos o las características de aquello a lo que se enfrenta. La sola asunción de que la información proporcionada de modo objetivo podrá ser valorada en todos aquellos espacios en los que existen estos elementos técnicos, pondrá al lego en una posición en la que sus derechos estarán en peligro al tiempo en que tal información no concede un soporte lo suficientemente firme para la expresión de su voluntad.

Para tales efectos, la construcción del deber de consejo se constituye como un medio de apoyo al proceso deliberativo del individuo, ahí donde es previsible que no pueda ser desarrollado autónomamente de manera adecuada, conformándose de modo diverso a la "mera recomendación amistosa a la que hace referencia el art. 2119". ${ }^{27}$ En este sentido, debe observarse a modo de reforzamiento y profundización del de mera información, considerando que supone "hacer aparente a la otra parte las consecuencias y oportunidad de la celebración del contrato previsto", ${ }^{28}$ o de "una explicación de los hechos y la valoración de alternativas de decisión". ${ }^{29}$ Implica, en consecuencia, una apreciación que orienta la decisión de la otra parte, ${ }^{30}$ de modo que el contenido del mensaje transmitido deja de ser neutro, como en el caso del deber de información. Deberán atenderse las particularidades del sujeto con quien se pretende contratar, en términos de asistirlo en la comprensión de las cláusulas contractuales o respecto a los elementos relacionados con el objeto mismo de la prestación, considerando especialmente los intereses y necesidades declarados por éste o conocidos por la contraparte durante la fase de tratativas preliminares. Como destaca CHARDIN, el deber de consejo implica de parte de quien lo concede, una preparación de la decisión personalizada, en todos los casos en los que la preparación general (dispuesta principalmente por medio de la información que el legislador pudiese ordenar poner en conocimiento de la otra parte), no resulte suficiente ni adecuada. ${ }^{31}$

Conforme al mismo deber, se deberán dar a conocer las consecuencias ventajosas y los inconvenientes de las diferentes alternativas posibles, ${ }^{32} \mathrm{de}$

\footnotetext{
${ }^{27}$ Barros y Rioseco, cit. (n. 1), p. 642.

${ }^{28}$ Ghestin, Loiseau y Serinet, cit. (n. 11), pp. 1314-1315.

${ }^{29}$ Barros y Rioseco, cit. (n. 1), p. 634.

${ }^{30}$ Fil, cit. (n. 16), p. 73; Ghestin, Loiseau y Serinet, cit. (n. 11), p. 1315.

${ }^{31}$ Chardin, cit. (n. 26), p. 156.

${ }^{32}$ Fabre-Magnan, Muriel, De l'obligation d'information dans les contrats. Essai d'une théorie, LGDJ, París, 2014, p. 9.
} 
haberlas, tomando en consideración los móviles y circunstancias particulares de su co-contratante que, conocidas por la otra, le inducirían a la celebración del contrato. ${ }^{33}$ De este modo, como señala Hernández Paulsen, se pretende orientar "a los clientes cuyos conocimientos, experiencia o cualificación les impiden comprender adecuadamente la respetiva operación, en el sentido de que por lo menos deben prevenirles, en su caso, acerca de la inconveniencia de la misma para sus intereses". ${ }^{34}$ Así, si bien el medio a utilizar es idéntico al empleado en el deber de información (el mensaje), una primera distancia se encuentra en su finalidad específica, $\mathrm{y}$, a partir de tal diferencia, un conjunto de elementos que se centran en su naturaleza, sus requisitos de procedencia y la forma en la que ella debe ser satisfecha. A partir de lo anterior, se ha indicado que se trata de una obligación de medios, ${ }^{35}$ aunque, nuevamente, creemos que debe efectuarse una prevención, puesto que, a nuestro juicio, dicha calificación debe darse sólo a aquella fase intelectual del deber de consejo, ${ }^{36}$ en la que el transmisor efectivamente debe desplegar conductas diligentes para efectos de averiguar los intereses y necesidades de la contraparte al tiempo de preparar y formular el mensaje, pero no se extiende a su transmisión que, al igual que el deber de mera información, se comporta en este ámbito como una obligación de resultado. ${ }^{37}$

\section{JUSTIFICACIÓN DEL DEBER DE CONSEJO}

Ahora bien, podrá observarse que el punto de partida, al menos desde la lógica de la codificación civil, puede ser negativa en torno a apreciar la necesidad de construir un deber de consejo. ${ }^{38} \mathrm{Si}$ ya el deber de información se ha presentado con carácter excepcional, a fortiori, una obligación de mayor intensidad parece ajena al planteamiento general del codificador. Cada parte, por regla general, deberá premunirse de la información, sea o no técnica, que

\footnotetext{
${ }^{33}$ Fabre-Magnan, cit. (n. 32), p. 387.

${ }^{34}$ Hernández Paulsen, Gabriel, La obligación precontractual de la entidad de crédito de informar al cliente en los servicios bancarios y de inversión, Marcial Pons, Madrid, 2014, p. 130.

${ }^{35}$ Bernard de Saint Affrique, Jean, "Du devoir de conseil”, Deffrenois, 1995, Vol. 115, Nº 1, p. 924 ; BOUCARD, cit. (n. 17), p. 23; KHOURY, cit. (n. 19), p. 27.

${ }^{36}$ BouCARD, cit. (n. 17), p. 24.

37 Ídem.

${ }^{38}$ Barros y Rioseco, cit. (n. 1), p. 634, advirtiendo que "el mero consejo o información, sin otra calificación, no da lugar a responsabilidad, a menos que haya una razón para entender que existe un deber de entregarlos o de diligencia en su expresión".
} 
resulte necesaria para prestar su voluntad para la celebración del contrato. Conforme a ello, se advierte que no existe en todo caso, y en forma universal, ni un deber de información, ni, menos aún, un deber intensificado de consejo. ${ }^{39}$ Su construcción a partir de la buena fe deberá considerar algunas circunstancias particulares de la relación que se pretende constituir, ${ }^{40}$ las que deben impactar en su naturaleza, a fin de no dejarlas a "vagas consideraciones morales", ${ }^{41}$ y cuyos contornos pretendemos precisar a continuación.

\subsection{La formulación y la crítica al deber precontractual de consejo como deber fiduciario}

En primer término, cabe preguntarse si la consideración de los intereses del otro en la esfera de las tratativas preliminares, como ha sido deducida por la jurisprudencia ampliando el campo de aplicación de la buena fe, impone siempre un deber de cooperación para la satisfacción de los intereses de las partes; y, además, deberá apreciarse si acaso debe incluirse en dicho deber una intensidad tal que, en todo caso, pueda importar la postergación de los intereses personales por parte de su deudor, a modo de deberes fiduciarios. ${ }^{42}$ Nos interesa advertir lo anterior puesto que, al tiempo de configurarse un deber de consejo, suponiendo el reconocimiento y la consideración de los intereses particulares de su beneficiario, una formulación de tal magnitud podría incluso conllevar que su deudor debería rechazar la celebración del contrato al advertir que sus términos podrían resultar insatisfactorios para la contraparte o, incluso, situarlo en una posición de riesgo previsible, dando cuenta de una especie de obligación preventiva de seguridad.

Esta idea no sólo implicaría reconocer aquellos aspectos conforme a los cuales puede suponerse, utilizando los criterios expansivos de la buena fe, una magnitud tal de la confianza depositada por parte de uno de los sujetos en la otra, que ameriten la configuración de un deber de asesoramiento en el ámbito precontractual, ${ }^{43}$ sino que también el ordenamiento estaría posicionando a una de las partes en una posición de garante respecto a otra

\footnotetext{
${ }^{39}$ Romain, cit. (n. 3), p. 858.

${ }^{40}$ Entendiendo, como lo hacen Barros y Rioseco, cit. (n. 1), p. 642, que las fuentes de este deber pueden encontrarse en el contrato, o derivarse su responsabilidad del acto ilícito o de alguna disposición legal, como se expresa en el $\$ 657$ II del BGB.

${ }^{41}$ Mouly-Guillemand, cit. (n. 13), p. 395.

${ }^{42}$ Barros y Rioseco, cit. (n. 1), p. 649.

${ }^{43}$ Romain, cit. (n. 3), p. 850; Barros y Rioseco, cit. (n. 1), p. 644.
} 
al tiempo de la contratación, como una especie de guardián de sus derechos. Ello implicaría que el deber de consejo se extendería a bastante más que la sola recomendación, y, advertidas las necesidades del otro, estas se situarían en una escala mayor que los propios intereses. Esta posición parece haber tomado en ciertos casos nuestra Corte Suprema, al resolver que: “(...) tanto la doctrina como la jurisprudencia de esta Corte Suprema ha considerado a la buena fe, en su aspecto objetivo, como la conducta que puede esperarse de un hombre correcto, puesto que es un estándar de conducta, que al darle contenido es empleado como sinónimo de probidad, lealtad, confianza, seguridad, honorabilidad, de no contradicción del comportamiento observado y fair play o juego limpio, considerando, en su caso, la función económica que tienen los negocios jurídicos, que impone la cooperación, colaboración, asesoramiento e información entre las partes, comportándose de manera activa, pues le asiste la obligación de salvaguardar el interés de la otra parte, en un contrato". ${ }^{44}$

El punto de partida se encuentra en la identificación de las bases del vínculo negocial sobre su configuración como una relación de confianza, conformada en torno a la idea de los mentados deberes fiduciarios. ${ }^{45}$ Cabe apreciar, sin embargo, que la conceptualización de la relación fiduciaria ha sido bastante imprecisa. ${ }^{46}$ No obstante, existe un cierto consenso en que tales deberes se fundamentan en la idea de la realización de ciertas conductas en beneficio de otros, ${ }^{47} \mathrm{o}$, al menos, en evitar cualquier tentación de sacrificar el interés del beneficiario favoreciendo el propio. ${ }^{48} \mathrm{El}$ problema que persiste, en todo caso, reside en que determinar el contenido específico de los deberes que emanan de ella, lo que implica, en primer término, identificar la relación

${ }^{44}$ Corte Suprema, 2 de septiembre de 2014, Rol N 14.243-2013 (el destacado es nuestro). En igual sentido ya se había pronunciado la Corte Suprema, 2 de mayo de 2012, Rol N 3965-2011; Corte Suprema, 25 de abril de 2012, Rol ํ 7145-2010; y Corte Suprema, 27 de enero de 2012, Rol N ${ }^{\circ}$ $1180-2011$.

${ }^{45}$ Romain, cit. (n. 3), p. 850, observa que, debido a la relación de confianza que articula la buena fe objetiva, pueden establecerse deberes fiduciarios. En ellos agrupa los deberes de lealtad (desde la idea de la cooperación) y los deberes de moderación respecto al co-contratante, cuya extensión dependerá de las particularidades objetivas de la situación contractual o precontractual.

${ }^{46}$ DeMotт, Deborah A., "Beyond metaphor: an analysis of fiduciary obligation", Duke Law Journal, $1998, \mathrm{~N}^{\circ} 5$, p. 879.

${ }^{47}$ Scott, Austin W., "The fiduciary principle”, California Law Review, 1949, Vol. 37, N 4, pp. 539555, p. 540; EdELman, James, "The role of status in the law of obligations", en: Gold, A.; Miller, P.B. (eds.), Philosophical foundations of fiduciary law, Oxford University Press, Nueva York, 2014, pp. 23-27.

${ }^{48}$ Getzler, Joshua, "Ascrining and limiting fiduciary obligations. Understanding the operation of consent”, en: Gold, A.; Miller, P.B. (eds.), Philosophical foundations of fiduciary law, Oxford University Press, Nueva York, 2014, p. 41. 
existente entre dos sujetos como una de carácter fi duciario, a pesar de que el ordenamiento no haya efectuado tal califi cación de manera expresa, ${ }^{49} \mathrm{ni}$ haya otorgado datos sufi cientes para construirla, por ejemplo, identificando una relación íntimamente ligada a la noción de confi anza, como ocurre paradigmáticamente en el contrato de mandato (artículo 2116 CC). De ahí que tal caracterización suele deducirse de los casos en que se han conferido ciertos poderes a una persona que pueden terminar por afectar los intereses de otra ${ }^{50} \mathrm{de}$ modo que la confi guración de tales deberes se aprecia tomando en cuenta que el fi duciario siempre debe responder a la confi anza especialmente depositada por el interesado ${ }^{51} \mathrm{y}$, en consecuencia, actuar iluminado por la satisfacción de tales intereses.

Al efecto, un deber fi duciario podría implicar, no sólo un comportamiento que considere los intereses de la contraparte, sino incluso la sustitución de la decisión misma de contratar. Ello se observa, por ejemplo, en la regulación del mandato, cuando el artículo $2149 \mathrm{CC}$ dispone que "(e)l mandatario debe abstenerse de cumplir el mandato cuya ejecución sería manifiestamente perniciosa al mandante". Pero deberá indagarse si acaso el deudor del deber de consejo estaría de algún modo obligado a abstenerse de la celebración del contrato, incluso en aquellos casos en los que haya advertido a la contraparte de la inadecuación o de los riesgos y eventuales perjuicios que signifi caría para él el hecho mismo de la contratación. Nos parece que por mucho que la enunciación general de la buena fe dada por la jurisprudencia antes citada utilice un lenguaje en este sentido, a modo de salvaguarda de los legítimos intereses del otro, una formulación tan extensa terminaría lesionando los sustentos dogmáticos de la autonomía privada, utilizando un principio del derecho para configurar una suerte de incapacidad de los sujetos. ${ }^{52}$ Ya nos decía Domat, que el consejo se califi ca como tal puesto que persiste la libertad de hacer o no hacer aquello que fue aconsejado o recomendado, ${ }^{53} \mathrm{y}$, con ello, a menos que la fuerza de las circunstancias efectivamente sitúe a una de las partes en posición de garante de la otra, el deber de asesoramiento no queda absorbido por el cumplimiento de

${ }^{49}$ Conaglen, Matthew, Fiduciary loyalty. Protecting the due performance of non-fi duciary duties, Hart Publishers, Oxford-Portland, 2010, pp. 7 ss.

${ }^{50}$ DeМотт, cit. (n. 46), p. 908.

${ }^{51}$ DeMotT, cit. (n. 46), p. 911.

${ }^{52}$ De la Maza Gazmuri, Iñigo, "El suministro de información como técnica de protección de los consumidores: los deberes precontractuales de información", Revista de Derecho (Universidad Católica del Norte), 2010, Año 17, $\mathrm{N}^{\circ} 2$, p. 35.

${ }^{53}$ Domat, cit. (n. 1), p. 454. 
esta clase de deberes fiduciarios. Con ello, quien carga con dicho deber le dará pleno cumplimiento mediante la transmisión del mensaje particularizado en las necesidades del otro contratante, ilustrándolo de los contornos del contrato que se ajusten (o no) a sus intereses, pero, efectuado lo anterior, quedará en el arbitrio de este último la celebración (o no) del contrato o la aceptación (o no) de sus términos particulares sobre las bases del consejo recibido. ${ }^{54}$

\subsection{La formulación del deber de consejo sobre la base de la confianza basada en el carácter profesional de una de las partes y la legítima ignorancia de la otra respecto de los elementos técnicos del contrato}

Una vez justificada la existencia del deber de consejo en la magnitud de la relación de confianza existente entre las partes, deberá tenerse en cuenta la forma en la que esta se despliega en un contexto más general, como es el que se aprecia en los casos en los que existe una acusada asimetría entre las partes, dada paradigmáticamente por el ámbito profesional en el que actúa el proveedor y la legítima ignorancia de su co-contratante. La intensidad de tales elementos nos permitirá, asimismo, deslindar el deber de consejo de otro de carácter específico, como es el "deber de alerta" o "de advertencia", cuya finalidad es destacar de modo más patente los elementos negativos o eventualmente nocivos o perjudiciales que pueden derivarse de la contratación.

i.) Sobre la intensidad normal de los elementos a ser considerados para la configuración de un deber de consejo.

Un punto crucial para la construcción del deber de consejo parece encontrarse en la constatación de las dificultades técnicas para la identificación de las necesidades propias que pretenden ser satisfechas por medio de la contratación. Como advierte Demogue a partir de la idea de la colaboración y la finalidad del contrato, "el profesional sabe que su cliente se acerca a él en virtud de los conocimientos especiales que espera aprovechar". ${ }^{55}$ De tal forma, continúa, el profesional se encuentra de cara a un no-profesional, ignorante de las cosas que la profesión importa, circunstancia que no puede ser utilizada por aquél para promover la celebración de contratos que resulten desastrosos

\footnotetext{
${ }^{54} \mathrm{~V}$. BouCARD, cit. (n. 17), p. 23, al señalar que el deudor del deber de consejo no se transforma en el director de la conciencia de la otra parte, puesto que tal actitud constituiría un atentado manifiesto a su libertad. Así, el deber de consejo no comporta la obligación de rechazar la celebración del contrato. Debe orientarse la acción de una persona, pero no tomar la decisión en su lugar.

${ }^{55}$ Demogue, cit. (n. 4), p. 28.
} 
para el cliente, ${ }^{56} \mathrm{o}$, agregamos con menos dramatismo, al menos desviados de la consecución de sus intereses. ${ }^{57}$

Conforme a lo anterior, nos parece que son dos los elementos que darán lugar al deber de consejo, cuya intensidad dará cuenta también de la amplitud o profundidad de la forma en la que se debe llevar a cabo la asistencia: el elemento técnico y las calidades de profano y profesional de quienes participan en la negociación. ${ }^{58}$

En primer término, el carácter técnico puede darse tanto en los casos en los que la comprensión del objeto de la prestación requiere de ciertos conocimiento, destrezas o competencias que sólo una de las partes posee, ${ }^{59}$ y que, por tanto, no lograrían ser convenientemente resueltas por medio del solo recurso a la formulación de un deber de información (por mucha claridad, sufi ciencia y oportunidad con la que se les dé cumplimiento). Ejemplo de lo anterior encontramos en el caso en que se disponga la adquisición de un aparato que tenga un complejo nivel de tecnología, de modo tal que el comprador medio ignore legítimamente el significado de los usuales anglicismos y tecnicismos que suelen emplearse para la identificación de sus características.

Pero, en segundo lugar, también se dará en los casos en los que, si bien los propósitos puntuales pueden ser razonablemente identificados por ambas partes, las dificultades técnicas se producen en torno a la formulación de las cláusulas contractuales, mediando o no una negociación previa (aunque con mayor impacto en este último caso), en los que tampoco la mera transmisión de un mensaje objetivo (la identificación de tales cláusulas) no puede lograr una protección adecuada. Expresión paradigmática de lo anterior se encuentra en el deber de asesoramiento dispuesto en materia de seguros, tanto respecto a la compañía (artículo 529, núm. 1 CCom), como del corredor (artículo 57

\footnotetext{
${ }^{56}$ Ídem.

${ }^{57}$ Este aspecto también puede observarse desde la idea del abuso de debilidad, confianza o dependencia, en los casos en los que, como expresa Palazón GarRido, María Luisa, "El abuso de debilidad, confianza o dependencia", en: Sánchez Lorenzo, S. (ed.), Derecho contractual comparado. Una perspectiva europea y transnacional, Thomson Reuters - Civitas, Cizur Menor, 2016, $3^{\text {a }}$ edición, T. I, p. 1304, "el contratante beneficiado no crea las condiciones de abuso (como sucede en los vicios de dolo o intimidación), pero sí las aprovecha para obtener la perfección de un contrato en condiciones ventajosas". La idea se advierte, por ejemplo, en el artículo 3.2.7 de los Principios Unidroit; el artículo 4:109 PECL; y el artículo 7:207 DCFR.

${ }^{58}$ En este sentido, BARRos y RiosECO, cit. (n. 1), p. 645, se refieren a la conocida asimetría de experiencia en la materia del consejo.

${ }^{59}$ A modo de ejemplo, Mouly-Guillemand, cit. (n. 13), p. 407 refiere a la forma de utilización de un bien, o, en términos más generales, como la manera de servirse del objeto, en términos de su funcionamiento o de su montaje.
} 
del Decreto Ley $N^{\circ} 251$, de 1931). En ellos, la explicitación legal del deber se justificaría por el mayor desequilibrio que se puede presentar entre las partes en atención a las complejidades que representa el contrato de seguro, tanto en su dimensión económica como jurídica ${ }^{60}$ y en que la asimetría de información y conocimiento técnico podría, sin medidas de resguardo resultantes de tal evidencia, provocar un desajuste entre las necesidades del asegurado y el contrato finalmente celebrado con la aseguradora. Lo anterior, considerando especialmente que tanto el corredor como la compañía de seguros actúan bajo estándares de profesionalidad o, como señalaría Hernández Paulsen, forman parte de un campo de intenso carácter técnico, ${ }^{61} \mathrm{y}$, agregamos, ampliamente regulado.

No obstante, el deber de consejo supone un fuerte contenido técnico del contrato que sólo una de las partes posee a cabalidad, y de ahí que puedan ofrecerse mayores distancias con el deber de información. Conforme a lo anterior, si el tipo de contrato a ser celebrado es plenamente asible por el contratante medio, sea en referencia a su contenido o al objeto de la prestación, bastará con comunicar adecuada y suficientemente los elementos más relevantes de aquellos, sin más. De no ser de este modo, toda forma de contratación, especialmente en la esfera del consumo, conllevaría el asesoramiento del proveedor, y, con ello, se terminaría por entorpecer y encarecer el tráfico ahí donde no resulta necesario. Lo anterior, sin perjuicio de los casos en los que el propio proveedor ha ofrecido la posibilidad de asesoramiento o se ha puesto en posición de prestarlo ante el requerimiento efectuado por la contraparte, integrándolo, en consecuencia, a la dinámica de la negociación.

Así, pueden detectarse una multiplicidad de situaciones en los que pueden apreciarse casos en los que una de las partes actúa bajo el conocimiento de la "legítima ignorancia" 62 de la contraparte, la que no puede ser solucionada a partir de la sola entrega de la información objetiva y general, sino que debe ser complementada por un actuar diligente al tiempo de ofrecer una orientación integral respecto a la conveniencia, oportunidad y riesgos de la celebración del contrato. ${ }^{63}$ En estos casos, deberá observarse que, más allá de expresar

\footnotetext{
${ }^{60}$ Khoury, cit. (n. 19), p. 27.

${ }^{61}$ Hernández Paulsen, cit. (n. 34), p. 130.

${ }^{62}$ Chinchilla Imbett, Carlos Alberto, "El deber de información contractual y sus límites", Revista de Derecho Privado, Vol. 21, 2011, p. 339.

${ }^{63}$ BoucARD, cit. (n. 17), p. 25, advierte que, en estos casos, por mucho que se haya dado cumplimiento a los deberes de información, igualmente podrá sancionarse al profesional por haber omitido el cumplimiento el deber de consejo.
} 
una voluntad fundada en la libertad, el contrato se formará únicamente sobre la base de la decisión afirmativa del profano. ${ }^{64}$ Su posición le impedirá inmiscuirse realmente en los contornos de la prestación, los que sólo podrá conocer a partir de la transmisión del mensaje especializado que recibe de parte del profesional, y, con ello, se genera una relación intensa de confianza en la veracidad y exactitud del consejo. ${ }^{65}$

Sin embargo, debemos comprender que también es necesario constatar que quien aparece como deudor del deber de consejo efectivamente tenga los conocimientos y destrezas técnicas que le permitan identificar adecuada y suficientemente los intereses de la contraparte y, conforme a ellos, proponga o negocie los términos de un contrato ajustado a ellos, o, en el extremo, rechace su celebración. Por ello, especialmente en los casos en los que se advierte tal desbalance, puede apreciarse que el deber de consejo se sustenta, aun mediatamente en la buena fe, sobre el deber más cercano del actuar profesional, ${ }^{66}$ destacado por la superioridad técnica de uno de los intervinientes en la negociación. ${ }^{67}$ Desde la base de dicha profesionalidad, en los que se advierte un campo de carácter técnico, ${ }^{68}$ podrá comprenderse que la manifestación concreta del deber de asesoramiento consiste en una opinión fundada en criterios propios de la lex artis, la que se termina por expresar mediante la transmisión de un mensaje que se resuelve en el consejo de contratar o no contratar, y, en el primer caso, de qué manera el contrato recomendado satisface las necesidades e intereses del otro. ${ }^{69}$ Con ello, a diferencia del simple deber de información, que supone que la "parte ignorante" logra ponderar aisladamente la conveniencia de la contratación, el deber de consejo implica que, en el marco de dicha actividad deliberativa, aquél debe ser orientado, ${ }^{70}$ acompañado y asistido en el proceso de reflexión. ${ }^{71}$ En suma, dicho consejo implica poner

\footnotetext{
${ }^{64}$ Chardin, cit. (n. 26), pp. 65-66. obtención de un consejo adecuado a las necesidades del sujeto. Demogue, cit. (n. 4), p. 18.

${ }^{67}$ LuCAs de Leyssac, cit. (n. 10), p. 21.

${ }^{68}$ Boucard, cit. (n. 17), p. 21; Hernández Paulsen, cit. (n. 34), p. 130.

${ }^{69}$ Khoury, cit. (n. 19), p. 78.

${ }^{70}$ Llobet i Aguado, cit. (n. 23), p. 34.

${ }^{71}$ Hernández Paulsen, cit. (n. 34), p. 130.
}

${ }^{65}$ Como señalan BArros y Rioseco, cit. (n. 1), p. 646, en este ámbito los consejos no se plantean en la práctica sobre la mera base de la amistad, sino por parte de profesionales o especialistas. Desde esta idea, la confianza depositada se justifica, en cuanto a su intensidad, en la expectativa razonable de

${ }^{66}$ Para unas primeras aproximaciones del influjo del carácter profesional de una de las partes en la formulación del deber de cooperación de las partes, especialmente en la fase precontractual, vid. 
en su conocimiento las consecuencias ventajosas y los inconvenientes de las diferentes alternativas posibles, ${ }^{72}$ deteniéndose especialmente en aquellos aspectos que pueden impactar en el propósito perseguido o tener consecuencias en sus derechos. ${ }^{73}$ Entre ellos se incluye la recomendación de no contratar, tomando en consideración los móviles y circunstancias particulares de su cocontratante que le inducirían a la celebración del contrato. ${ }^{74}$

No obstante, aun cuando se ha llegado a sostener que "la relación profesional transforma el deber de informar en un verdadero deber de aconsejar", ello puede ser excesivo, ${ }^{75}$ y dependerá, según el caso, de las particularidades de la relación jurídica, conforme estamos advirtiendo. ${ }^{76} \mathrm{~A}$ partir de lo anterior podrá sostenerse que el carácter profesional de una de las partes, como asimismo el contenido técnico del contrato, podrá situar al profano en una posición en la que entrega su confianza al primero en la cooperación en la toma de decisión. ${ }^{77} \mathrm{El}$ descanso de este último en la confianza que supone del consejo profesional puede darse de modo expreso, por ejemplo, cuando éste es directamente solicitado ${ }^{78} \mathrm{o}$, cuando, atendidas las circunstancias, es razonable anticipar que se está tomando una decisión sobre la base del consejo entregado, aunque no haya sido solicitado. ${ }^{79}$

Lo anterior, que también tiene relevancia para la identificación de la intensidad o profundidad del consejo, ${ }^{80}$ supone ponderar tanto las particularidades de la contraparte con relación a sus propias destrezas técnicas, como la magnitud de las complejidades del objeto o del tipo de contrato propuesto. Con ello, advirtiendo la existencia de las capacidades de la contraparte o la simplicidad del contrato o del objeto de la prestación, no podrá sostenerse la idea de la "legítima ignorancia" ni la necesidad de una tutela intensificada como la que supone el deber de consejo, siendo suficiente el

\footnotetext{
${ }^{72}$ Fabre-Magnan, cit. (n. 32), p. 9.

${ }^{73}$ FiL, cit. (n. 16), pp. 72 y 73.

${ }^{74}$ FABRe-Magnan, cit. (n. 32), p. 387.

${ }^{75}$ Mouly-Guillemand, cit. (n. 13), p. 396, agrega que el carácter profesional de una de las partes podrá permitir presumir el conocimiento de la información que deba ser transmitida, pero no será suficiente para configurar un deber de información, y, menos aún, agregamos, un deber de consejo.

${ }^{76}$ Gómez Calle, cit. (n. 21), p. 120.

${ }^{77}$ Lucas de Leyssac, cit. (n. 10), p. 333; Boucard, cit. (n. 17), p. 45.

${ }^{78}$ Dugdale, A.M.; Stanton, K.M., Professional negligence, Butterworths, Londres, 1982, p. 19.

${ }^{79}$ Dugdale y Stanton, cit. (n. 78) p. 22.

${ }^{80} \mathrm{La}$ calidad de especialista -nos indica PICOD, cit. (n. 4), p. 116- permite aumentar las obligaciones de quien debe informar y agravar la responsabilidad de su beneficiario, según el caso.
} 
cumplimiento de los deberes de información, e, incluso, la carga de informarse de dicha contraparte. ${ }^{81}$

Por ello, no puede desconocerse que, incluso en estos casos, alguna actitud es esperable desde el contratante ignorante. En primer término, porque la actitud de prudencia que impera en las normas civiles exige un comportamiento diligente, aunque en este caso se encuentre matizado por las dificultades técnicas antes apuntadas. No observar el punto importaría, por un lado, incentivar que la contratación se tome con ligereza, ${ }^{82} \mathrm{y}$, por otro, que en todo caso sería necesario configurar un deber fiduciario de intensidad tal en que la decisión de contratar o no dependería únicamente del profesional, lo que ya hemos controvertido como un razonamiento extremo que priva de capacidad a los sujetos. Más allá del razonamiento que puede advertirse desde la lógica civil, el punto también aparece reflejado en nuestra LPDC, al menos desde la perspectiva de la información, al establecer como un deber del consumidor el informarse responsablemente (art. 3 , inc. $1^{\circ}$, letra c LPDC), aunque estimemos que dicho deber (que se presenta más bien como una carga), se encuentre incluso normativamente subordinado al derecho de recibir del proveedor información veraz y oportuna. ${ }^{83}$

En segundo lugar, deberá considerarse que la formulación del consejo requiere de la cooperación de su beneficiario para que pueda llevarse a cabo la asesoría. Sin perjuicio de que trataremos este punto algo más adelante, podemos anticipar la idea indicando que si se requiere que una parte contemple y considere los intereses particulares de la otra, será necesario que esta última comunique fidedignamente cuáles son tales intereses. Como ya se ha indicado, el deber de asesoramiento significa un actuar diligente de quien se encuentra en la posición de dar el consejo, pero dicha diligencia supone que éste ha desplegado sus esfuerzos en advertir las necesidades e intereses de la contraparte, pero sin llegar al extremo de tener que realizar actividades de investigación que superen los deslindes de un comportamiento leal. Si la información sobre las circunstancias puntuales de la otra parte no se encuentra ya en su poder, o no son fácilmente obtenibles de fuentes públicas de información, la diligencia se

\footnotetext{
${ }^{81}$ No puede dejar de advertirse, como hace GHestin, LoISEAu y Serinet, cit. (n. 11), p. 1255, que el mismo deber de información se ha construido tomando en especial consideración el desequilibrio entre las partes en la relación contractual, por lo que su configuración se ha advertido como esencial en la relación entre el profesional y el profano, bajo la ilusión de reposicionar a las partes y, con ello, poder regresar a la lógica de la autonomía privada.

${ }^{82}$ Romain, cit. (n. 3), p. 859.

${ }^{83}$ Sobre el particular, vid. Corte de Apelaciones de Santiago, 24 de marzo de 2015, Rol No 1535-2014.
} 
centrará en consultar a la otra parte sobre las particularidades del caso, y, sobre ellas, elaborar la recomendación que la buena fe le impone.

ii.) Sobre la intensidad extrema de los elementos a ser considerados para la formulación del deber de asesoramiento y su reformulación como deber de alerta.

Sin perjuicio de lo anterior, deberá distinguirse el deber de consejo con el "deber de alerta", en el que el profesional debe advertir que la celebración del contrato puede configurar un riesgo tal que termine situando a la contraparte en una posición de inseguridad, incluso previendo la posibilidad de daño. ${ }^{84}$ Este deber, que se ha designado también como "obligación de previsión", "deber de guía" ${ }^{85}$ " "deber de advertencia", ${ }^{86}$ también se encontraría fundado en la buena fe, suponiendo que, debido al conocimiento técnico de un profesional, éste debe dar cuenta de las consecuencias negativas que la propia celebración o una cierta ejecución del objeto del contrato puede significar. ${ }^{87}$ Aquí cabe preguntarse si aún estamos en la esfera del deber de consejo, y que, en consecuencia, basta con una advertencia materializada en la recomendación, destacado por sus eventuales consecuencias negativas; o si acaso el estándar de conducta diligente impone al profesional un deber adicional de impedir la contratación, incluso ante la desatención del consejo brindado. La solución, a nuestro juicio, sigue dependiendo de las circunstancias fácticas y de la intensidad de la relación existente entre las partes.

El punto de partida volverá a ser que la relación no plantea normalmente la constitución de deberes fiduciarios, de tal modo que el cumplimiento del deber de alerta se satisfaría en la indicación precisa de la posibilidad de daño y, en su caso, las medidas de prevención o de carácter curativo que se deben tomar en caso de que el daño efectivamente se presente. La conducta del transmisor de tal mensaje será valorada en torno a la suficiencia, claridad y oportunidad en la que aquel ha sido entregado, como asimismo en la forma en la que la posibilidad de daño fue destacada al tiempo de hacerlo. Pero, nuevamente, cumplidos tales estándares, la decisión del beneficiario de contratar (o no) o de adoptar (o no) las precauciones o las medidas curativas recomendadas

\footnotetext{
${ }^{84}$ Así, Demogue, cit. (n. 4), p. 28, se pone especialmente en el caso del profesional que vende explosivos, quien tiene el deber de indicar al comprador las medidas para protegerse de la explosión.

${ }^{85}$ Bernard de Saint Affrique, cit. (n. 35), p. 918.

${ }^{86}$ Barros y Rioseco, cit. (n. 1), p. 634.

${ }^{87}$ Gross, Bernard, La notion d'obligation de garantie dans le droit des contrats, Librairie Générale de Droit et de Jurisprudence, París, 1964, pp. 211 y 212; BoucArD, cit. (n. 17), p. 24.
} 
por el transmisor le seguirán siendo imputables, por cuanto el daño le ha sido convenientemente anticipado y se ha producido única y exclusivamente por no haber seguido las recomendaciones que ha recibido al efecto. Así se reconoce en la venta de medicamentos, en los que, al amparo de lo dispuesto en el artículo 96 del Código Sanitario y de los artículo 81, letra b) y 199, letra d) del Reglamento del sistema nacional de control de los productos farmacéuticos de uso humano (Decreto $\mathrm{N}^{\circ} 3$, de 2010, del Ministerio de Salud), el folleto de información al paciente debe contener las advertencias necesarias para la utilización segura y efectiva, señalando las contraindicaciones, interacciones y reacciones adversas, cuando corresponda.

Excepcionalmente, el "deber de alerta" degenerará en la sustitución de la contraparte en su decisión respecto a la contratación. ${ }^{88}$ Para ello, será necesario que efectivamente una de las partes se encuentre en posición de garante respecto a la otra, la que se justificará en la extrema intensificación de los elementos designados en el punto anterior: un ámbito puramente técnico de las prestaciones a ser efectuadas, complementado por un actuar profesional en el que la lex artis suponga un máximo nivel de diligencia y en que la ignorancia del sujeto se encuentre legitimada por los contornos mismos de la prestación. Ejemplos de lo anterior los hallamos en ciertos casos de la actividad médica, en la que la posición de garante se desprende de la propia relación médico-paciente, incluso en los casos en los que no existe propiamente un vínculo contractual, ${ }^{89}$ cuando se encuentra innecesariamente en riesgo la vida o la integridad física del paciente. Aunque, en estos casos, la solución probablemente se dará desde la negativa a la contratación por parte del profesional, sin alterar con ello sus deberes en la medida en la que se está frente a una causa objetiva y no discriminatoria (artículo 3, inc. 1, letra c, LPDC).

\section{EL CONTENIDO IMPLÍCITO DEL DEBER DE CONSEJO}

Ya resuelta la existencia y magnitud del deber de consejo, cabe observar la forma en la que esta debe llevarse a cabo a partir de su contenido implícito. Lo anterior supone configurar ciertos deberes y cargas que corren en ambas direcciones, dado que es comprensible que el consejo quede condicionado por los intercambios de información llevados a cabo entre las partes y que, como

\footnotetext{
${ }^{88}$ Ghestin, Loiseau y Serinet, cit. (n. 11), p. 1315

${ }^{89}$ MAyer Lux, Laura, "Autonomía del paciente y responsabilidad penal médica", Revista de Derecho P. Universidad Católica de Valparaíso, 2011, XXXVII, p. 388.
} 
tales, se fundamentan en la relación de confianza y profesionalidad que nutre la dinámica del proceso de contratación. ${ }^{90}$ Cabrá recordar que nos encontramos en el ámbito de la cooperación que deben dar las partes a efectos que la prestación negocial sea realmente satisfactoria, de lo que resulta que no por el hecho de estar frente a un profano, este no se encuentra en una posición tal de asistir e informar al profesional de todos los elementos que le son requeridos para la confección de la recomendación. Al efecto, podemos distinguir los siguientes aspectos:

\section{El deber del profesional de informarse}

El punto de partida se encuentra en el actuar diligente del profesional en la preparación del consejo. Por ello, éste deberá investigar los elementos relevantes que deben ser aislados para constatar los aspectos que resultan esenciales de conocer con la finalidad de poder prestar una asesoría adecuada. De lo contrario, el consejo puede ser inútil, o, incluso, nocivo. ${ }^{91}$ Lo anterior supone la necesaria identificación de las necesidades y particularidades del sujeto que pretende la contratación, bajo una idea que se ha expresado como el deber de "informarse para informar" (o, en este caso, "informarse para asesorar" ${ }^{92}$ o "buscar pasara saber". ${ }^{93}$ En consecuencia, es deber del profesional tomar la iniciativa en la investigación,${ }^{94} \sin$ esperar que sea la otra parte quien, carente de conocimientos o habilidades específicas, proporcione la información que resulte suficiente para la elaboración del consejo. Al efecto, debemos volver a la idea del deber de profesionalidad, que, en este punto, le impone la realización de conductas dirigidas a la obtención de la información necesaria para prestar el consejo. Para ello, deberá considerarse que el propio carácter técnico del contrato o de la prestación derivada de éste provocará que, en la mayor parte de los casos, su contraparte no se encuentre en posición de indicar suficientemente todos los aspectos que pueden resultar relevantes para concretar la adecuación contractual a sus necesidades e intereses, $\mathrm{y}$, conforme a ello, será el profesional quien deberá efectuarle las consultas del caso, de manera suficiente y comprensible. Lo anterior, a menos que la información ya se encuentre en su poder (por ejemplo, en razón de otras relaciones

\footnotetext{
${ }^{90}$ KhOURY, cit. (n. 19), p. 27.

${ }^{91}$ Bernard de Saint Affrique, cit. (n. 35), p. 916.

${ }^{92}$ Picod, cit. (n. 4), p. 121; Hernández Paulsen, cit. (n. 34), p. 132.

${ }^{93}$ Bernard de Saint Affrique, cit. (n. 35), p. 916.

${ }^{94}$ KHOURY, cit. (n. 19), p. 109.
} 
contractuales concertadas con anterioridad) o se encuentren dispuestas en bases de información de acceso público (por ejemplo, en el ámbito del crédito al consumo, la información disponible para la banca en materia de protestos y morosidades, de conformidad a los Decretos $\mathrm{N}^{\circ}$ 950, de 1928 y $\mathrm{N}^{\circ} 1971$, 1945, del Ministerio de Hacienda, al artículo 14 de la Ley General de Bancos y a los Capítulos 18-5 y 20-6 de la Recopilación Actualizada de Normas de la Superintendencia de Bancos e Instituciones Financieras).

Resuelto lo anterior, corresponde al profesional efectuar ciertas valoraciones en torno al contenido contractual o al objeto de la prestación. Conocidas que han sido las particularidades el sujeto, la intencionalidad del consejo debe situarse en la pretensión de su debido ajuste. Para tales efectos, se descartarán aquellos elementos que se desvían de la necesidad expresada (por ejemplo, el ofrecimiento de bienes o servicios innecesarios, tales como pólizas de seguros que cubren riesgos que el asegurado no puede experimentar) o se incorporarán otros tantos que, aunque no forman parte del negocio principal, resultan indispensables para la satisfacción (por ejemplo, la recomendación de adquirir elementos de seguridad adicional ante la advertencia de un riesgo). Ahora bien, si ello no es posible, puesto que el profesional no cuenta con un producto o no puede prestar el servicio manera tal que se produzca el citado ajuste, deberá advertirlo al cliente, $\mathrm{y}$, de conocer la existencia de una alternativa en el mercado, debería indicársela como resultado final de la recomendación.

\section{La carga de informar por parte del profano}

Por la otra, la "parte ignorante" tiene la carga de proporcionar la información que le sea requerida de manera veraz para provocar el ajuste que el deber de consejo pretende..$^{95}$ En este caso, la calificación de carga se advierte porque su infracción provoca un debilitamiento de sus propios derechos, $\mathrm{y}$, aunque no prevista de modo expreso en el ámbito del consejo, se deduce también de la cooperación fundada en los pilares de la buena fe. ${ }^{96}$ En este caso, quien no ha prestado su colaboración en la identificación de sus necesidades, como tampoco en las particularidades de su situación, no podrá alegar con posterioridad la infracción del deber de consejo por la ausencia de la adecuación

\footnotetext{
${ }^{95}$ Ghestin, Loiseau y Serinet, cit. (n. 11), p. 1315, en el sentido de que la cooperación del acreedor del deber debe cooperar con su cumplimiento, para lo cual debe responder lealmente a las preguntas que le son formuladas al efecto.

${ }^{96}$ CABAnillas Sánchez, Antonio, Las cargas del acreedor en el Derecho civil y en el mercantil, Editorial Montecorvo, Madrid, 1998, pp. 254-255.
} 
del contrato a sus intereses. Así, si el profesional ha desplegado una conducta diligente para intentar obtener tal información, pero no lo ha logrado por la falta de cooperación del lego, la inadecuación no es imputable al primero, sino sólo al segundo. Ejemplos de lo anterior lo encontramos en la órbita del derecho de seguros, en referencia a la declaración del riesgo (artículo $525 \mathrm{CCom}),{ }^{97} \mathrm{y}$ respecto a la prestación de servicios de salud, en los que el artículo 26 de la Ley $\mathrm{N}^{\circ} 20.584$, que dispone que tanto la persona que solicita la atención, como sus familiares o representantes legales, deberán colaborar con los miembros del equipo de salud que la atiende, informando de manera veraz acerca de sus necesidades y problemas de salud y de todos los antecedentes que conozcan o les sean solicitados para su adecuado diagnóstico y tratamiento.

Por su parte, la comunicación efectuada debe ser completa en atención a los requerimientos indicados, de modo que la información transmitida deberá ajustarse a lo que, de buena fe, se encuentre en conocimiento del profano. Si acaso este tuviese dudas sobre el contenido de la información que debe ser transmitida, no queda más que su expresión al profesional para que, nuevamente sobre la base de la cooperación, esta pueda ser convenientemente resuelta. $\mathrm{Si}$ acaso la información conferida es falsa o incompleta, y el profesional no tiene otros medios para conocer de dicha situación, la consecuencia cargará sobre los hombros del lego. En este sentido, por ejemplo, en el ámbito de las operaciones bancarias se dispone incluso de una sanción penal para "[e]1 que obtuviere créditos de instituciones de crédito, públicas o privadas, suministrando o proporcionando datos falsos o maliciosamente incompletos acerca de su identidad, actividades o estados de situación o patrimonio, ocasionando perjuicios a la institución" (artículo 160 de la Ley General de Bancos, contenida en el Decreto con Fuerza de Ley Nº 3, de 1997).

\section{El deber de transmisión del mensaje (consejo) del profesional}

Se trata éste del resultado final del intercambio informativo desplegado por las partes, y el que, en su momento, podrá resultar útil para medir la forma en la que se llevó a cabo el consejo. Esta fase, ya material, supone la entrega clara, precisa, oportuna y suficiente de todos los aspectos que se tuvieron en cuenta para su preparación (la "fase intelectual"), dando cuenta, en consecuencia, de los elementos tomados en consideración respecto a las

\footnotetext{
${ }^{97}$ Ríos Ossa, Roberto, El deber precontractual de declaración del riesgo en el seguro de daños, Thomson Reuters, Santiago, 2014, passim.
} 
circunstancias personales de su beneficiario, como de la forma en la que la contratación propuesta se ajusta a ellas. En el caso del "deber de alerta" este incluirá, adicionalmente, todos aquellos aspectos que resulten útiles para que el profano pueda premunirse ante los riesgos que entrañan los actos derivados de la utilización del bien o servicio, los que deberán ser considerados por éste al tomar la decisión de contratar (o no) o las precauciones que deberá tomar en caso afirmativo.

Como hemos señalado previamente, en esta etapa, la obligación es de resultado y se satisface con los estándares antes mencionados. A nuestro juicio, su cumplimiento no implica que el profesional deba velar porque su receptor efectivamente comprenda cabalmente todos los contornos relevantes del contrato que se le está ofreciendo conforme al consejo entregado. De no ser de este modo, se trataría de una obligación de casi imposible satisfacción, puesto que implicaría que el transmisor debería llevar a cabo una función pedagógica y valorativa que supera los contornos de una contratación que no esté enfocada en ella. Lo anterior, veremos más adelante, tiene relevancia para observar las consecuencias de su incumplimiento.

\section{CONSECUENCIAS DE LA INFRACCIÓN DEL DEBER DE CONSEJO}

En primer término, deberá apreciarse que, situándonos en una fase precontractual, el establecimiento de un deber de consejo que no esté cubierto por un contrato que la disponga propiamente como obligación no podría significar una pretensión de cumplimiento forzado. Adicionalmente, la casuística nos indicará que la problemática general se presenta en los casos en los que el contrato ya ha sido celebrado, e, incluso, las prestaciones ya han sido cumplidas, total o parcialmente, y sólo con posterioridad el destinatario argumenta la inadecuación del contrato a sus pretensiones particulares, motivadas por una falla en el deber de consejo. Siendo de tal modo, son muchos los casos en los que los mecanismos de ejecución formulado de modo a posteriori dejan de tener sentido, sin brindar apoyo alguno al destinatario del deber, ${ }^{98}$ en tanto un consejo otorgado tardíamente no podrá revertir aquella prestación ya realizada.

Conforme a lo anterior, el problema se centrará en otras medidas que pueda intentar el profano ante la infracción. Sobre el particular, se apreciará que en aquellos casos en los que el deber se encuentra tipificado, la reconducción

\footnotetext{
${ }^{98}$ BouCARD, cit. (n. 17), p. 446.
} 
está dada a las reglas de la responsabilidad. De este modo aparece en el artículo 529, núm. 1, CCom ("el asegurador será responsable de las infracciones, errores y omisiones cometidos y de los perjuicios causados a los asegurados"), solución que no se explicita en el caso que el seguro sea contratado por medio de un corredor de seguros (artículo 57 del Decreto Ley $\mathrm{N}^{\circ} 251$, de 1931). La indemnización de perjuicios también aparece como solución en el caso del consejo maliciosamente otorgado en el artículo $2119 \mathrm{CC}$, aunque se destaca que en este caso no hay otra solución posible dado que, conforme dispone la misma norma, no se producen otras obligaciones con relación a éste.

Una primera pregunta por resolver es si acaso la indemnización es la única herramienta con la que cuenta el lego, especialmente cuando pretende desligarse del objeto de la prestación que le resulta inadecuado a sus intereses. Al efecto, podrá advertirse que la solución también podrá darse por medio del error, en la medida en que se configure alguno de los presupuestos que la ley dispone al efecto, o, en casos más graves, por el dolo por omisión o reticencia del profesional, y, con ello, solicitar la nulidad del contrato. $\mathrm{Si}$ así fuese, no cabría más que detenerse en las diversas valoraciones que para el caso otorga DE la MAZA al tratar de los denominado deberes atípicos de información, ${ }^{99}$ que, entendemos, son igualmente aplicables en el caso del deber de consejo. Como se indicó previamente, entre ambos existe una línea bastante sutil, de modo que no se advierten inconvenientes para que, en este punto, se efectúen ponderaciones similares. Asimismo, deberá tenerse presente que, en caso de atenerse a la acción de nulidad, bien podrá solicitarse también la correspondiente indemnización de perjuicios (de haberse presentado y no haber quedado resueltos por medio de las prestaciones derivadas de dicha nulidad), cubriendo, en consecuencia, el interés negativo. ${ }^{100}$

No obstante dicho planteamiento general, sí cabe hacer algunas puntualizaciones. La decisión entre la nulidad, sea por error o sea por dolo, y la indemnización dependerán de ciertos factores adicionales, pero, en todo caso, de la pretensión del beneficiario del deber de consejo en cuanto tenga interés (o no) en mantener vigente el contrato, si es que acaso ello es posible. Por ejemplo, si en virtud de un inadecuado asesoramiento, el paciente se sometió

${ }^{99}$ De la Maza Gazmuri, Iñigo, "La distribución del riesgo y la buena fe. A propósito del error, el dolo y los deberes precontractuales de información", Revista de Derecho P. Universidad Católica de Valparaíso, 2011, XXXVII, pp. 115-135.

${ }^{100}$ López Díaz, Patricia, "Los supuestos y el alcance de la indemnización de daños como medio de tutela precontractual en el Código Civil chileno y su eventual confluencia con la indemnización por incumplimiento contractual", Ius et Praxis, 2018, Año 24, N 1, p. 274. 
a un tratamiento o a una operación que le produjo daños, la nulidad no le dejará en mejor posición, dado que no es posible dejar sin efectos, al menos, la prestación ya realizada por el médico. En estos casos, la alternativa se centrará en la indemnización de los perjuicios experimentados, que, implicando la subsistencia del contrato, se conducirán por la vía de la responsabilidad contractual en la medida en la que se producirá una proyección sobre el contenido del contrato, derivando en problemas de incumplimiento. ${ }^{101}$

Por su parte, en lo que se refiere a la inexcusabilidad del error, podrá advertirse que, en este plano, el profano se encuentra en mejor situación respecto a los problemas que se presentan en el campo de la mera información. El intenso carácter técnico del contrato o del objeto de la prestación lo situará en posición de legítima ignorancia, ${ }^{102}$ por lo que la liberación de sus consecuencias pasará por la prueba que pudiese rendir el profesional para destacar que, en las circunstancias puntuales, se trataba de una persona que bien podría haberse protegido por sí misma, o, alternativamente, que había obtenido un consejo por parte de un tercero, el que decidió seguir.

En lo que se refiere al régimen de responsabilidad, cuestión que también calla la única norma que se refiere al punto en materia de seguros, el problema se presentará al tiempo en que se evidencie que estamos ante la infracción de un deber precontractual. En este sentido, observamos que la identificación de sus efectos (la inadecuación del contrato o del objeto de la prestación) se observará normalmente al tiempo en que el contrato ya ha sido celebrado. En consecuencia, coincidimos con quienes, en este caso, han advertido que el régimen apropiado es el que se refiere a la responsabilidad contractual, puesto que estos elementos han incidido en el hecho mismo de la contratación, ${ }^{103}$ a menos que, siguiendo la tesis de López Díaz, se advierta la posibilidad de opción de anular el contrato (siempre que se configuren los requisitos específicos al efecto), dando curso a una responsabilidad propiamente precontractual. ${ }^{104}$

Si nos situamos en este punto de partida, la persecución de cualquier responsabilidad derivada de la infracción del deber de consejo importará, en primer término, que su supuesto beneficiario deberá comprobar su existencia, asignándose a éste la carga de la prueba conforme a los términos generales

\footnotetext{
${ }^{101}$ LóPEZ DíAz, cit. (n.100), p. 274.

${ }^{102}$ Sosteniéndose, incluso, que dicha ignorancia legítima está sujeta a una suerte de presunción, de tal manera que el profesional debe actuar, en principio, ajustando su conducta a la idea de estar frente a un profano. Cfr. LuCAS de Leyssac, cit. (n. 10), p. 337; Picod, cit. (n. 4), p. 125.

${ }^{103}$ De la Maza, cit. (n. 21), p. 47.

${ }^{104}$ López Díaz, cit. (n.100), p. 275.
} 
del artículo 1698 CC. Para ello, si no está cubierto por disposición legal o por la costumbre (también objeto de prueba), deberá dar cuenta de los elementos indicados en el apartado anterior para su fundamentación y, con ello, expresar que éste emana de la buena fe en virtud de la naturaleza de la obligación. ${ }^{105}$ Comprobado lo anterior, la acción deberá enfocarse en el incumplimiento del deber, sea por el hecho de que no se efectuó asesoramiento alguno, sea por el hecho de que, a pesar de haber sido prestado el consejo, este no logró su finalidad en atención a la falta de diligencia de su deudor. El resultado dañoso deberá haber sido, en consecuencia, la inadecuación del contrato a las necesidades de la parte no-profesional, mediante la lógica de la comparación entre el contrato que debió haberse celebrado si se hubiesen tenido en consideración de tales intereses y especialidades y el que efectivamente concluyeron las partes. ${ }^{106}$

La pregunta que resulta de lo anterior es cuál es la justificación de la reparación del mentado daño. Al respecto, se han planteado varias posibilidades, dependiendo, como ya ha quedado dicho, si se ha procedido por vía de responsabilidad precontractual, cubriendo el interés negativo; o, en el caso de dirigirse por la vía contractual, independiente de la resolución, solicitando el resarcimiento del interés positivo, sujetándose a los criterios generales del daño patrimonial (como daño emergente, principalmente en virtud de los gastos en los que se debió incurrir para subsanar la inadecuación; o lucro cesante, por las pérdidas de ganancias experimentadas por el mismo hecho), sin descontar la posibilidad de accionar por concepto de daño moral, de haberlo. ${ }^{107}$

Una propuesta paralela, sin desconocer necesariamente lo anterior, se concentra en atender a que, de contar con la información y consejo adecuados, el profano podría haber desplegado una conducta que impidiese la celebración del contrato en los términos en los que fue ofrecido o hubiese tomado las medidas para limitar los riesgos derivados de éste. Conforme a lo anterior, el daño se establecería bajo la idea de la pérdida de la oportunidad. ${ }^{108}$ Sobre este último punto parece razonar la Corte Suprema, al sostener que el hecho de no haberse dado un diagnóstico adecuado frente a un examen previo (por un

\footnotetext{
${ }^{105}$ En este sentido, Corte Suprema, 14 de febrero de 2017, Rol No 35.121-2016.

${ }^{106}$ LUCAS DE LeYSSAC, cit. (n. 10), p. 340.

${ }^{107}$ Obsérvese que en el contexto del Derecho inglés se ha llegado a similar resultado. En South Australia Assett Management Corporation v York Montague Ltd (1997) AC 191, Lord Hoffmann indicó que: "Si el deber es de aconsejar si un curso de actuación debe o no ser tomado, entonces el asesor debe tomar los cuidados razonables para considerar todas las consecuencias potenciales de tal curso de acción. Si es negligente, deberá ser responsable por todas las pérdidas previsibles que son consecuencias de tal curso de acción" (traducción propia).

${ }^{108}$ BOUCARD, cit. (n. 17), p. 448.
} 
profesional que ni siquiera tenía competencia para ello), "constituyó la causa directa del retraso en el correcto diagnóstico de la actora, que, a su vez, le impidió acceder a un oportuno tratamiento y motivó que ella debiera someterse (sic) una serie de procedimientos y prestaciones médicas que, de haberse pesquisado la enfermedad con anterioridad, habrían sido distintos, En otras palabras, si bien el cáncer que aquejaba a la actora ya estaba presente con anterioridad y su pronóstico era incierto, se le privó de la chance de evitar que su gravedad se siguiera extendiendo y de tratarlo de manera acertada, adecuada y -quizás- eficaz, obligándola a incurrir en gastos producto de prestaciones médicas cuya necesidad, en caso de un diagnóstico previo, habría sido evaluada de manera diferente". ${ }^{109}$

Conforme a ello, el parámetro de comparación se situará en evaluar si se ha desplegado la diligencia correspondiente a su lex artis, propia de su profesionalidad, a efectos de identificar las necesidades y particularidades del sujeto y del negocio, y si se ha utilizado dicha información, también diligentemente, para efectos de la elaboración y entrega del consejo que efectivamente se ajuste a las necesidades del profano para efectos de la contratación. En el caso indicado, el carácter técnico que envuelve el actuar sanitario califica al paciente como quien se encuentra en legítima ignorancia, $\mathrm{y}$, al presentarse ante quien reviste el carácter de profesional (aunque no haya estado correctamente habilitado para ello), se configura una intensa relación de confianza. En estos casos, no bastaba una mera información por parte del profesional, sino el consejo para seguir una cadena de tratamientos y procedimientos para impedir la propagación de la enfermedad. Omitido lo anterior, u otorgado directamente un mal consejo, el tribunal entiende que, más allá de la recuperación de todo cuanto había gastado en procedimientos que, a la vez, resultaron inútiles e inadecuados, el principal rubro indemnizatorio estuvo en la pérdida de la chance de haber sido asistida en mejores términos.

Finalmente, el profesional podrá liberarse de responsabilidad comprobando que su deber se encuentra extinguido, en los mismos términos a los indicados en el artículo $1698 \mathrm{CC}$, de modo tal que deberá acreditar que entregó el consejo bajo los estándares referidos de suficiencia, claridad y oportunidad (recordando, que, en esta esfera, la obligación es de resultado), o, en su caso, rendir prueba de las conductas activas desplegadas para la adecuada preparación de dicho mensaje, desde la satisfacción de aquellas gestiones

${ }^{109}$ Corte Suprema, de 29 de junio de 2018, Rol N 35.721-2017. 
destinadas a informarse de las particularidades, necesidades e intereses de la contraparte, como aquellas llevadas a cabo con la finalidad de propiciar el mentado ajuste con el tenor contractual o con el objeto mismo de la prestación. Dado que la tendencia ha sido la calificación de esta fase intelectual como una obligación de medios, su incumplimiento devendría de la ausencia de una diligencia integradora, entendiendo que la culpa constituye, en estos casos, un elemento configurador del citado incumplimiento. ${ }^{110}$ Es aquí donde el profesional también podrá liberarse de responsabilidad si acaso comprueba la ausencia de cooperación de su contraparte, quien no ha sido diligente o fidedigno en la entrega de la información necesaria para provocar la mentada adecuación, en la medida que dicha información no fuese pública o, al menos, ya se encontrase a su disposición.

\section{CONCLUSIONES}

En el ámbito de las relaciones contractuales, el impacto del dominio expansivo de la buena fe ha permitido reconocer vínculos de confianza y estándares de lealtad y cooperación durante todo el íter contractual. Conforme a ellos, se ha posibilitado un mayor campo de aplicación de los deberes de información, especialmente de naturaleza precontractual, justificados especialmente en la asimetría existente entre las partes. Lo anterior es especialmente acusado en el contexto de las relaciones de consumo, donde la herramienta de la información es dispuesta como un mecanismo fundante de protección (y favorito de nuestro legislador), acaso suponiendo que el consumidor adecuadamente informado puede hacerse completamente responsable de los resultados de la contratación. Esta formulación impide observar que son muchos los contextos, especialmente aquellos en que nos enfrentamos a mercados fuertemente regulados o en que los bienes y servicios transados tienen altos componentes técnicos, en los que la mera dotación de la información (aun clara, suficiente y oportuna) no confiere al lego un nivel de resguardo adecuado.

Una alternativa para subsanar dicho problema consiste en averiguar si, nuevamente de acuerdo a los parámetros de la buena fe, es posible contextualizar supuestos en los que la transmisión objetiva y abstracta de información no es suficiente, requiriendo de un mayor grado de colaboración por parte del profesional.

${ }^{110}$ Pizarro Wilson, Carlos, "La culpa como elemento constitutivo del incumplimiento de las obligaciones de medio o de diligencia", Revista de Derecho P. Universidad Católica de Valparaíso, 2008, XXXI, passim. 
Tales circunstancias, si bien han sido enunciadas de modo general por nuestra jurisprudencia, no ha recibido un tratamiento sistemático por parte de nuestra doctrina, incluso en los casos en los que el ordenamiento jurídico ha explicitado un deber de consejo que supera las finalidades de la mera información. Si bien los límites entre uno y otro se presentan de modo bastante difuso, especialmente porque su resultado es siempre un mensaje, hemos pretendido distinguirlos en cuanto a su finalidad, operatoria y consecuencias de su infracción.

Así, caracterizando el deber de consejo por su integración en el proceso deliberativo del sujeto, se pretende una orientación adecuada por parte del profesional en torno a la conveniencia o inconveniencia de la contratación. Desde esta perspectiva, supone un ajuste del contrato a las particularidades y necesidades de un sujeto puntual, razón por la cual, implícitamente, advierte ciertos deberes del profesional de informarse y cargas del contratante lego de informar todo aquello que puede ser relevante para propiciar el ajuste. Con ello, el incumplimiento del deber de consejo deberá reconocerse no sólo en la ponderación del resultado (el mensaje), sino en la diligencia llevada a cabo para su preparación. Así también, más allá de una respuesta fundada en la responsabilidad del profesional, deberá observarse el eventual impacto que su ausencia puede haber tenido en la formación del consentimiento, para analizar si acaso existe un vicio de nulidad (basado en el error o en la reticencia) y si el contratante lego desea o no acudir a tal herramienta, dependiendo de su intención (o utilidad) de conservar o no el contrato.

\section{BIBLIOGRAFÍA}

\section{A) DOCTRINA}

BARRIENTOS ZAMORANO, Marcelo, "El deber precontractual de información en el contrato de seguro, un producto financiero y de consumo: Estudio de sus fuentes", Revista Chilena de Derecho, 2015, Vol. 42, n² 2, pp.423-451.

Barros, Enrique; Rioseco, Andrés, "Responsabilidad de quien da un mal consejo", en: Vidal Olivares, Á.; Severín Fuster, G.; Mejías Alonso, C., (eds.), Estudios de Derecho Civil X. Jornadas Nacionales de Derecho Civil. Valparaíso, 2014, Thomson Reuters La Ley, Santiago, 2015, pp. 633-651.

Bernard de Saint Affrique, Jean, "Du devoir de conseil", Deffrenois, 1995, Vol. 115, N 1, pp. 913-925.

Berthiau, Denis, Le principe d'égalité et le droit civil des contrats, LGDJ, París, 1999. 
BoucARD, François, Les obligations d'information et de conseil du banquier, Presses Universitaires d'Aix-Marseille, Aix-en-Provence, 2002.

Cabanillas Sánchez, Antonio, Las cargas del acreedor en el Derecho civil y en el mercantil, Editorial Montecorvo, Madrid, 1998.

Chardin, Nicole, Le contrat de consommation de crédit et l'autonomie de la volonté, Librairie Générale de Droit et de Jurisprudence, París, 1988.

Chinchilla ImBetT, Carlos Alberto, "El deber de información contractual y sus límites", Revista de Derecho Privado, Vol. 21, 2011, pp. 327-350.

Conaglen, Matthew, Fiduciary loyalty. Protecting the due performance of non-fiduciary duties, Hart, Oxford /Portland, 2010.

De la Maza Gazmuri, Iñigo, "Tipicidad y atipicidad de los deberes precontractuales de información", Revista de Derecho P. Universidad Católica de Valparaíso, 2010, XXXIV, pp. 75-99.

De la Maza Gazmuri, Iñigo, "Consentimiento informado, una visión panorámica”, Ius et Praxis, Año 16, n², 2010, pp. 89-120.

De la Maza Gazmuri, Iñigo, "El suministro de información como técnica de protección de los consumidores: los deberes precontractuales de información", Revista de Derecho (Universidad Católica del Norte), 2010, Año 17, $\mathrm{n}^{\circ} 2$, pp. 21-52.

De la Maza Gazmuri, Íñigo, "La distribución del riesgo y la buena fe. A propósito del error, el dolo y los deberes precontractuales de información", Revista de Derecho P. Universidad Católica de Valparaíso, 2011, XXXVII, pp. 115-135.

Demogue, René, Traité des obligations en général. II. Effets des Obligations, Librairie Arthur Rousseau, París, T. VI, 1931.

DeMotT, Deborah A., "Beyond metaphor: an analysis of fiduciary obligation", Duke Law Journal, 1998, n 5, pp. 879-924.

Domat, Jean, Les loix civiles dans leur ordre naturel, Jean Baptiste Coignard \& Librairie ordinaire du Roi, París, 1689.

Dugdale, A.M.; Stanton, K.M., Professional negligence, Butterworths, Londres, 1982.

EDElman, James, "The role of status in the law of obligations", en: Gold, A. y Miller, P. B. (eds.), Philosophical foundations of fiduciary law, Oxford University Press, Nueva York, 2014, pp. 21-38.

Eyzaguirre Baeza, Cristián; Rodríguez Diez, Javier, "Expansión y límites de la buena fe objetiva - A propósito del Proyecto de Principios Latinoamericanos de los Contratos", Revista Chilena de Derecho Privado, 2013, n 21, pp. 137-216.

Fabre-Magnan, Muriel, De l'obligation d'information dans les contrats. 
Essai d'une théorie, LGDJ, París, 2014.

FiL, Patrice, L'obligation d'information et de conseil en matière d'assurance, Presses Universitaires d'Aix-Marseille, Aix-en-Provence, 1996.

Getzler, Joshua, "Ascrining and limiting fiduciary obligations. Understanding the operation of consent", en: Gold, A. y Miller, P. B. (eds.), Philosophical foundations of fiduciary law, Oxford University Press, Nueva York, 2014, pp. 39-62.

GHEStin, Jacques; Louseau, Grégoire y Serinet, Yves-Marie, La formation du contrat, LGDJ, París, T. I., 2013.

GLANSDORFF, François, "Introduction générale”, en: Glansdorff, F. (coord.), Les obligations d'information, de renseignement, de mise en garde et de conseil, Lancier, Bruselas, 2006, pp. 7-50.

Gómez CALLE, Esther, Los deberes precontractuales de información, La Ley, Madrid, 1994.

Gross, Bernard, La notion d'obligation de garantie dans le droit des contrats, Librairie Générale de Droit et de Jurisprudence, París, 1964.

Guzmán Brito, Alejandro, "La buena fe en el Código Civil de Chile", Revista Chilena de Derecho, 2002, Vol. 29, n 1, pp. 11-23.

HeRnández Paulsen, Gabriel, La obligación precontractual de la entidad de crédito de informar al cliente en los servicios bancarios y de inversión, Marcial Pons, Madrid, 2014.

KHoury, Hichem, L'information et le conseil dus preneur d'assurance, , Presses Universitaires D’Aix-Marseille, Aix-en-Provence, 2011.

Llobet I Aguado, Josep, El deber de información en la formación de los contratos, Marcial Pons, Madrid, 1996.

LóPEz DíAz, Patricia, "Los supuestos y el alcance de la indemnización de daños como medio de tutela precontractual en el Código Civil chileno y su eventual confluencia con la indemnización por incumplimiento contractual", Ius et Praxis, 2018, Año 24, n 1, pp. 243-292.

LuCAS DE LeYsSaC, Claude, "L'obligation de renseignement dans les contrats", en : Loussouarn, Y. ; Lagarde, P. (dirs.), L'information en Droit privé, Librairie Générale de Droit et de Jurisprudence, París, 1978, pp. 305-341.

MAYer Lux, Laura, "Autonomía del paciente y responsabilidad penal médica”, Revista de Derecho P. Universidad Católica de Valparaíso, 2011, XXXVII, pp. 371-413.

Mazeaud, Denis, "Solidarisme contractuel et réalisation du contrat," en: Grynbaum, L.; Nicod, M. (eds.), Le solidarisme contractuel, Economica, Paris, 2004, pp. 57-71. 
McMeel, Gerard; VIGGO, John, Financial advice and financial products. Law and liability, Oxford University Press, Oxford, 2001.

Mouly-Guillemand, Clémence, Retour sur l'article 1135 du Code Civil. Une nouvelle source du contenu contractuel, LGDJ, París, 2006.

Palazón Garrido, María Luisa, "El abuso de debilidad, confianza o dependencia", en: Sánchez Lorenzo, S. (ed.), Derecho contractual comparado. Una perspectiva europea y transnacional, Thomson Reuters / Civitas, Cizur Menor, 2016, $3^{\text {a }}$ edición, T. I, pp. 1303-1335.

PICOD, Yves, Le devoir de loyauté dans l'exécution du contrat, LGDJ, París, 1989.

Pizarro Wilson, Carlos, "La culpa como elemento constitutivo del incumplimiento de las obligaciones de medio o de diligencia", Revista de Derecho P. Universidad Católica de Valparaíso, 2008, XXXI, pp. 255-265.

Ríos Ossa, Roberto, El deber precontractual de declaración del riesgo en el seguro de daños, Thomson Reuters, Santiago, 2014.

RomaIn, Jean-Francois, Théorie critique du principe général de bonne foi en droit privé, Bruylant, Bruselas, 2000.

Scotт, Austin W., "The fiduciary principle", California Law Review, 1949, Vol. 37, n 4, pp. 539-555.

Stitchirin Branover, David, El mandato civil, Editorial Jurídica de Chile, Santiago, 2008, $5^{a}$ edición (actualizada por Gonzalo Figueroa Yáñez).

WieACKER, Franz, El principio general de la buena fe, Civitas, Madrid, 1977 (trad. José Luis Carro).

B) SENTENCIAS CITADAS

Corte Suprema, 27 de enero de 2012, Rol N 1180-2012.

Corte Suprema, 25 de abril de 2012, Rol N 7145-2010.

Corte de Apelaciones de Antofagasta, 2 de mayo de 2012, Rol N 373-2011.

Corte Suprema, 2 de mayo de 2012, Rol N 3965-2011.

Corte Suprema, 2 de septiembre de 2014, Rol No 14.243-2013.

Corte de Apelaciones de Santiago, 24 de marzo de 2015, Rol № 1535-2014.

Corte Suprema, 14 de febrero de 2017, Rol N 35.121-2016.

Corte Suprema, 29 de junio de 2018, Rol N³5.721-2017.

- South Australia Assett Management Corporation v York Montague Ltd (1997) AC 191: House of Lords, 20 de junio de 1996, texto en inglés, html, disponible en línea: https://www.bailii.org/uk/cases/UKHL/1996/10.html. 